\title{
Consensus on international guidelines for management of groin hernias
}

\author{
Nadine van Veenendaal ${ }^{1} \cdot$ Maarten Simons $^{2}$ - William Hope ${ }^{3}$. Sathien Tumtavitikul ${ }^{4}$. Jaap Bonjer ${ }^{1}$ on behalf of the \\ HerniaSurge Group
}

Received: 4 November 2019 / Accepted: 15 March 2020 / Published online: 6 April 2020

(c) Springer Science+Business Media, LLC, part of Springer Nature 2020

\begin{abstract}
Background Groin hernia management has a significant worldwide diversity with multiple surgical techniques and variable outcomes. The International guidelines for groin hernia management serve to help in groin hernia management, but the acceptance among general surgeons remains unknown. The aim of our study was to gauge the degree of agreement with the guidelines among health care professionals worldwide.

Methods Forty-six key statements and recommendations of the International guidelines for groin hernia management were selected and presented at plenary consensus conferences at four international congresses in Europe, the America's and Asia. Participants could cast their votes through live voting. Additionally, a web survey was sent out to all society members allowing online voting after each congress. Consensus was defined as $>70 \%$ agreement among all participants.

Results In total 822 surgeons cast their vote on the key statements and recommendations during the four plenary consensus meetings or via the web survey. Consensus was reached on 34 out of $39(87 \%)$ recommendations, and on six out of seven (86\%) statements. No consensus was reached on the use of light versus heavy-weight meshes (69\%), superior cost-effectiveness of day-case laparo-endoscopic repair (69\%), omitting prophylactic antibiotics in hernia repair, general or local versus regional anesthesia in elderly patients (55\%) and re-operation in case of immediate postoperative pain (59\%).

Conclusion Globally, there is $87 \%$ consensus regarding the diagnosis and management of groin hernias. This provides a solid basis for standardizing the care path of patients with groin hernias.
\end{abstract}

Keywords Inguinal hernias $\cdot$ International guidelines $\cdot$ Consensus conferences

Groin hernia repair is globally performed in more than 20 million patients per year [1-5]. Multiple surgical techniques exist to repair groin hernias with variable outcomes. Despite guidelines [6-8], there is significant worldwide diversity

The members of the HerniaSurge group are listed in Acknowledgements section.

Maarten Simons

m.p.simons@olvg.nl

1 Department of Surgery, Amsterdam University Medical Center, Amsterdam, The Netherlands

2 Department of Surgery, OLVG Hospital, Oosterpark 9, 1091 AC Amsterdam, The Netherlands

3 Department of Surgery, New Hanover Regional Medical Center, Wilmington, USA

4 Department of Surgery, Vichaiyut Hospital, Bangkok, Thailand in management of groin hernias, depending on surgeons' expertise, patients characteristics, local resources, reimbursement systems and cultural differences between regions.

In 2018, the HerniaSurge group, a joint initiative of seven scientific surgical societies with a focus on hernia surgery, published the first International Guidelines for Groin Hernia Management [9]. These guidelines were developed according to the Grades of Recommendation Assessment, Development and Evaluation (GRADE) system [10,11], and were endorsed by the European Hernia Society (EHS), the Americas Hernia Society (AHS), The Asian-Pacific Hernia Society (APHS), the Afro Middle East Hernia Society (AMEHS), the Australasian Hernia Society, the European Association for Endoscopic Surgery (EAES) and International Endohernia Society (IEHS) [12-18]. However, acceptance among general surgeons remains unknown. A modified consensus method was developed to gauge the degree of agreement with the guidelines among health care professionals. This 
manuscript presents the outcomes of consensus conferences both in-person and online.

\section{Methods}

The International Guidelines on Groin Hernia Management were developed by a working group of 50 hernia experts, called the 'HerniaSurge' group [9]. All experts had clinical and scientific expertise in groin hernia surgery. Research questions were formulated and assigned to groups of two or three experts. Critical appraisal of the literature was performed according to Evidence-Based Medicine (EBM) rules and the GRADE approach $[11,19,20]$. During several meetings, results were discussed within the working group. Chapters were written and statements and recommendations were formulated. The Appraisal of Guidelines for Research and Evaluation (AGREE) II instrument was used for the guideline development process to ensure the highest standard for quality [21]. Finally, the guidelines were validated by three external reviewers.

A face-to-face expert consensus meeting among the HerniaSurge members was held in Rotterdam on June 5th 2016 to discuss the final statements and recommendations. A modified Delphi method was used. All statements and recommendations with level of evidence were presented. Discussion was initiated by presenting a summary of the reviewed literature pertaining to that specific topic. The experts voted on the eligibility of each recommendation for voting at international plenary consensus conferences. Refraining from voting was not allowed. Statements and recommendations that all HerniaSurge members agreed on were included for the plenary consensus conferences. Finally, 46 items from the international guidelines for groin hernia management were selected as most important and renewing (See "Appendix").

\section{International plenary consensus conferences}

Plenary consensus conferences were organized at four international congresses: the European Hernia Society (EHS) Congress 2016 in Rotterdam, The Netherlands; the European
Association for Endoscopic Surgery (EAES) Congress 2016 in Amsterdam, The Netherlands; the Asian-Pacific Hernia Society (APHS) Congress 2016 in Tokyo, Japan; and the Americas Hernia Society (AHS) Congress 2017 in Cancun, Mexico. Forty-six key statements and recommendations were presented at each conference chaired by an independent coordinator $(\mathrm{NvV})$.

Before the start of each congress, society members were e-mailed with the announcement of the plenary consensus conference. Additionally, a concept of the international guideline on groin hernia management was published online to provide background information prior to the consensus conferences.

At the plenary consensus conferences, key statements and recommendations were presented in seven categories: 'Groin Hernias,' 'General Aspects,' 'Open Groin Hernia Repair,' 'Laparo-endoscopic Groin Hernia Repair,' 'Bilateral, Femoral and Incarcerated Hernias,' 'Outcomes,' and 'Organization of Care.' All items were displayed with the original research question, the level of evidence and strength of the recommendation. Additionally, all congress delegates were asked four baseline questions about their profession, continental origin, yearly number of groin hernia repairs they performed and their preference for surgical repair method.

Congress delegates were given one minute per statement or recommendation to vote. There were three voting options for statements and four options for recommendations (Table 1). Voting at the plenary consensus conferences was performed using a digital voting system accessible via an app or online website. Consensus was defined as agreement by more than $70 \%$ of the participants.

Due to logistical reasons, live voting was not possible at the APHS in Tokyo. Alternatively, all statements and recommendations were presented in a plenary presentation and paper questionnaires were handed out to all congress delegates after the session. The paper questionnaires contained all statements and recommendations with the voting options. Completed questionnaires could be returned during the rest of the congress at the HerniaSurge booth in the main hall of the congress building.

After each congress, the 46 key statements and recommendations were entered into a web survey and sent by
Table 1 Answer possibilities at the plenary consensus conferences and web survey

\begin{tabular}{ll}
\hline Answer possibilities for statements & Answer possibilities for recommendations \\
\hline A. Agree with statement & $\begin{array}{c}\text { A. Agree with recommendation and } \\
\text { strength of the recommendation }\end{array}$ \\
B. Disagree with statement & B. Agree with recommendation only \\
C. Don't know & C. Disagree with recommendation \\
& D. Don't know
\end{tabular}


e-mail to all members of the corresponding hernia society. The e-mail referred to the recent plenary consensus conference. Members that were unable to attend the congress were invited to cast their vote through the online web survey. Voting options were the same as the abovementioned. There was no time limit to complete the web survey. The web surveys were launched after each congress, and open until April 1st 2017.

SPSS was used to analyze the outcomes per hernia society. A Chi-square test was performed to determine whether baseline characteristics differed between hernia societies.

\section{Results}

In total 822 (range 723-1072) participants cast their votes either in-person or online: 303 EHS delegates (213 on-site, 90 via web survey), 404 EAES members (181 on-site, 223 via web survey), 233 AHS delegates (84 on-site, 149 via web survey), and 132 APHS members (54 on-site, 78 via web survey). A majority of the participants was either a surgeon $(65,8 \%)$ or a hernia expert surgeon $(23,1 \%)$. Continental origin corresponded for all hernia societies, except for the APHS where 44,7\% (59/132) of the participants was from Asia. A similar group of 39\% (52/132) participants at this congress originated from Europe. The expertise among participants is reflected by yearly number of groin
Fig. 1 Annual number of groin hernia repairs per society member
Fig. 2 Preferred method of groin hernia repair ( $>60 \%$ of the cases) per society member
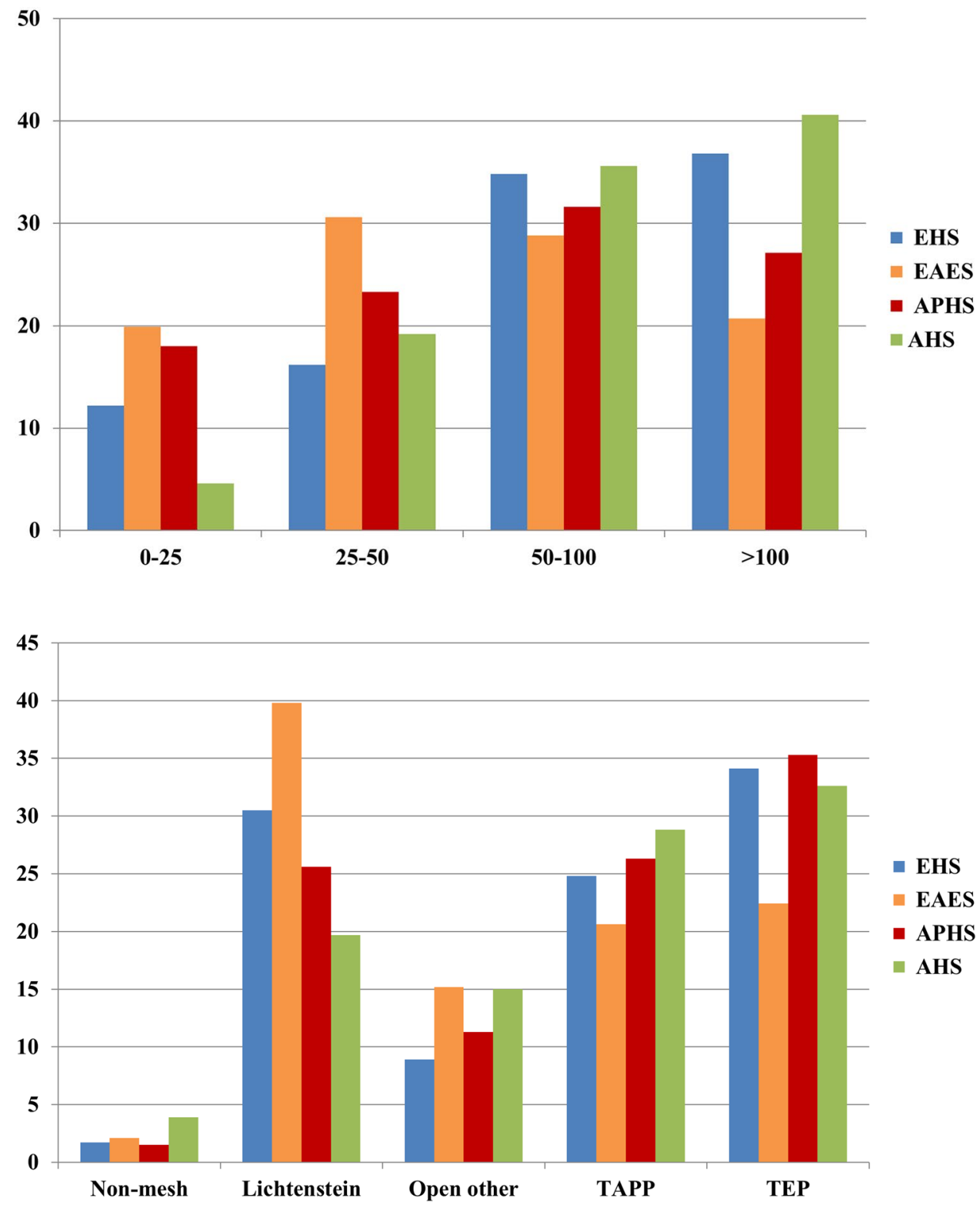
hernia repairs: $30,5 \%$ of the respondents performed over 100 repairs per year and 32,4\% performs $51-100$ repairs annually (Fig. 1). Preference for surgical technique was in $30,9 \%$ a Lichtenstein repair, in $29,6 \%$ a laparoscopic totally extraperitoneal repair (TEP) and $24,3 \%$ a transabdominal preperitoneal repair (TAPP) (Fig. 2).

Baseline characteristics were found not to be significantly different between hernia societies, $\chi^{2}(1)=46.06, p>0.05$. Level of Evidence (LoE), as determined by the HerniaSurge working group, will be provided after each statement or recommendation. The level of consensus (LoC) will be provided in the calculated percentage.

\section{Groin hernias}

Consensus was reached on all statements and recommendations in the category 'Groin Hernias' (Fig. 3).

There was consensus in $94 \%$ that the presence of a groin hernia can be confirmed by physical examination alone in the vast majority of patients with appropriate signs and symptoms (LoE: low; LoC: 94\%). Ultrasonography is the preferred imaging when there is doubt about the presence of a groin hernia [22] while MRI, CT or herniography are alternatives [23].
Intrinsic risk factors for the development of primary inguinal hernias include inheritance, a previous contra-lateral hernia, male gender, age and abnormal collagen metabolism [24-29]. Acquired risk factors for the development of primary inguinal hernias are previous prostatectomy and low body mass index [30-35]. Perioperative risk factors for recurrence like poor surgical technique, low surgical volume, and surgical inexperience should be considered in the management of groin hernia patients (LoE: low; LoC: 92\%).

The EHS classification system is suggested to stratify inguinal hernia patients for tailored treatment, research and audit (LoE: low; LoC: 81\%) [36].

Symptomatic groin hernias should be treated surgically. Asymptomatic or minimally symptomatic inguinal hernia patients may be managed with "watchful waiting" since their risk of hernia-related emergencies is low. The majority of these individuals will eventually require surgery, and surgical risks and the watchful waiting strategy should be discussed with patients (LoE: High; LoC: 89\%) [37-40].

\section{General aspects}

Consensus was reached on seven recommendations on 'General aspects' (Fig. 4). No consensus was reached on one statement and four recommendations. The statement

1. (R) Clinical examination alone is recommended for confirming the diagnosis of an evident groin hernia.

2. (R) Acquired, surgical and perioperative risk factors are recommended to be strongly considered since they are potentially modifiable and can influence the type of repair performed.

3. (R) Use of the EHS classification system for inguinal hernias is suggested for the purposes of performing research, tailoring treatments and performing quality audits.

4. (S) Although most patients will develop symptoms and need surgery, watchful waiting for minimal or asymptomatic inguina hernias is safe since the risk of hernia complications is low.

Management decision is made between the surgeon and patient.

5. (R) Discussions with patients about timing of hernia repair are recommended to involve attention to social environment, occupation and overall health. Lower morbidity of elelctive surgery has to be weighed against higher morbidity of emergency surgery.

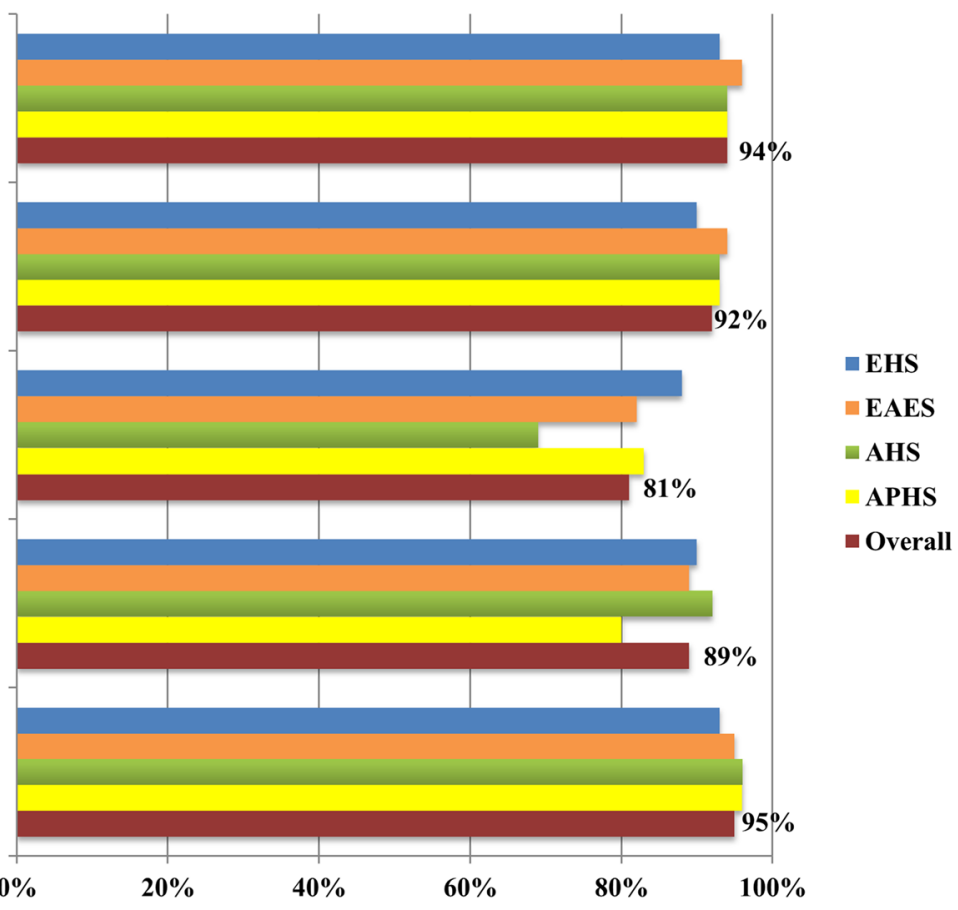

Fig. 3 Level of consensus for each statement and recommendation on Groin hernias 


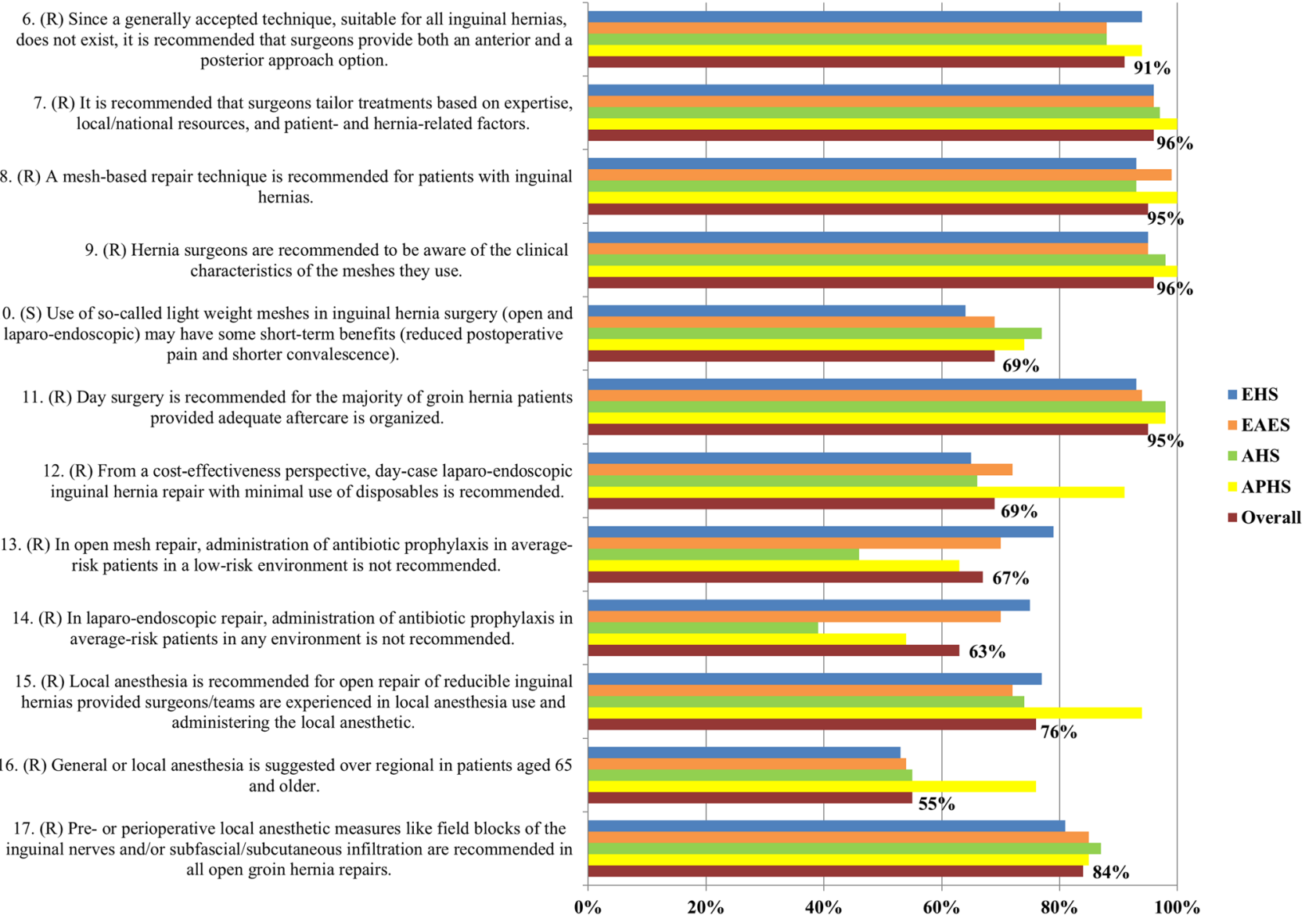

Fig. 4 Level of consensus for each statement and recommendation on General aspects

without consensus concerned the benefits of so-called lightweight meshes in inguinal hernia surgery (LoE: low; LoC: $69 \%$ ). The recommendations without consensus concerned the cost-effectiveness of day-case laparo-endoscopic surgery (LoE: moderate; LoC: 69\%), no antibiotic prophylaxis in average-risk patients in a low-risk environment in open mesh repair (LoE: high; LoC: 67\%), no antibiotic prophylaxis in average-risk patients in any environment in laparoendoscopic repair (LoE: low; LoC: 63\%) and general or local anesthesia over regional in patients aged 65 and older (LoE: low; LoC: $55 \%$ ).

One standard repair technique for all groin hernias does not exist. It is recommended that surgeons/surgical services provide both anterior and posterior approach options (LoE: very low; LoC: 91\%). Surgical treatment should be tailored to the surgeon's expertise, patient- and hernia-related characteristics and local/national resources (LoE: very low; LoC: 96\%) [41]. HerniaSurge suggests Lichtenstein or a laparo-endoscopic repair as optimal techniques. Provided that resources and expertise are available, laparo-endoscopic techniques have faster recovery times, lower chronic pain risk and are cost-effective [42-55].

Mesh repair is recommended as the first choice, either by an open procedure or a laparo-endoscopic repair technique (LoE: moderate; LoC: 95\%) [56]. Surgeons should be aware of the intrinsic characteristics of the meshes they use (LoE: low; LoC: 96\%).

Day surgery is recommended for simple groin hernia provided aftercare is organized and suggested for selected other cases (e.g., after local anesthetic in ASA III patients) (LoE: moderate; LoC: $95 \%)$ [55, 57, 58].

Local anesthesia in open repair has many advantages and is suggested to be used (especially in patients with severe systemic disease) provided the surgeon is experienced in this technique (LoE: high; LoC: 76\%) [59-64]. Perioperative field blocks are recommended in all cases of open repair (LoE: high; LoC: 84\%) [65-69]. 
18. (R) The Shouldice technique has lower recurrence rates than other suture repairs and is recommended in non-mesh inguinal hernia repair.

19. (S) The use of open non-mesh repair in specific patients or types (e.g. young males with lateral hernia L1) of inguinal hernia as an acceptable alternative to a Lichtenstein technique requires further studies.

20. (S) In open surgery there is insufficient evidence to recommend a pre-peritoneal mesh repair over Lichtenstein repair.

21. (R) Despite comparable results, three dimensional implants (plug-and-patch and bilayer) are not recommended because of the excessive use of foreign material, the need to enter both the posterior and anterior plane and the additional cost.

22. (R) Nerve anatomy awareness and recognition during surgery is recommended to reduce the incidence of chronic post-herniorrhaphy pain.

23. (R) During open surgery, planned prophylactic ilioinguinal nerve resection is not suggested since it does not reduce chronic pain incidence and it increases postoperative sensory loss.

24. (R) Pragmatic resection of the ilioinguinal nerve and/or the iliohypogastric nerve is recommended if iatrogenic nerve injury occurs or if the nerve(s) interfere(s) with mesh position.

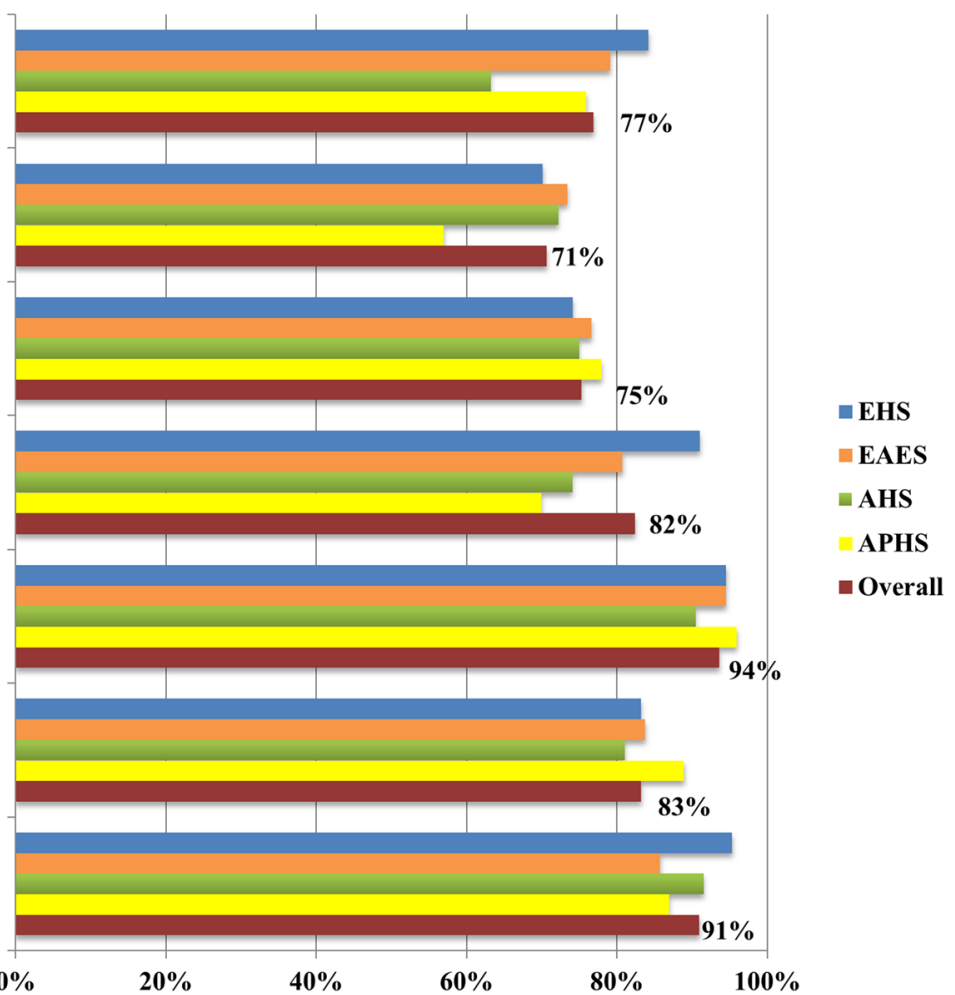

Fig. 5 Level of consensus for each statement and recommendation on Open groin hernia repair

\section{Open groin hernia repair}

Consensus was reached on all statements and recommendations on 'Open Groin Hernia Repair' (Fig. 5).

In open surgery, Lichtenstein repair is recommended over a pre-peritoneal mesh repair (LoE: very low; LoC: 75\%) [70, 71]. The use of open non-mesh repair in specific patients or types (e.g., young males with lateral hernia L1) of inguinal hernia as an acceptable alternative to a Lichtenstein technique requires further studies (LoE: low; LoC: 71\%).

In case a non-mesh inguinal hernia repair will be performed, the Shouldice technique is recommended since it has lower recurrence rates than other suture repairs (LoE: moderate; LoE: 77\%) [56].

Despite comparable results, three-dimensional implants (plug-and-patch and bilayer) are not recommended because of the excessive use of foreign material, the need to enter both the posterior and anterior planes and the additional cost (LoE: low; LoC: 82\%) [72-75].

Nerve anatomy awareness and recognition during surgery is recommended to reduce the incidence of chronic postherniorrhaphy pain (LoE: low; LoC: 94\%). During open surgery, planned prophylactic ilioinguinal nerve resection is not suggested since it does not reduce chronic pain incidence and it increases the incidence of postoperative sensory loss (LoE: low; LoC: 83\%) [76]. Pragmatic resection of the ilioinguinal nerve and/or the iliohypogastric nerve is recommended if iatrogenic nerve injury occurs or if the nerve(s) interfere(s) with mesh position (LoE: low; LoC: 91\%) [77].

\section{Laparo-Endoscopic groin hernia repair}

Consensus was reached on all statements and recommendations on 'Laparo-endoscopic Groin Hernia Repair' (Fig. 6).

For male patients with primary unilateral inguinal hernia, a laparo-endoscopic technique is suggested because of a lower postoperative pain incidence and a reduction in chronic pain incidence, provided that a surgeon with specific expertise and sufficient resources is available. However, there are patient and hernia characteristics that warrant a Lichtenstein as first choice (LoE: moderate; LoC: 73\%) [78].

TAPP and TEP have similar operative times, overall complication risks, postoperative acute and chronic pain incidence, and recurrence rates (LoE: moderate; LoC: $72 \%$ ) [78-86]. Since TAPP and TEP have comparable outcomes, 
25. (S) TAPP and TEP have similar operative times, overall complication risks, postoperative acute and chronic pain incidence and recurrence rates.

26. (R) In laparo-endoscopic inguinal hernia repair, TAPP and TEP have comparable outcomes; hence, it is recommended that the choice of the technique should be based on the surgeon's skills, education and experience.

27. (R) For male patients with primary unilateral inguinal hernia, a laparo-endoscopic technique is suggested because of a lower postoperative pain incidence and a reduction in chronic pain incidence.

28. (R) It is recommended that the contralateral groin be inspected at time of TAPP repair. If a contralateral inguinal hernia is found at the time of surgery and prior informed consent was obtained, repair is recommended.

29. (R) Mesh fixation is recommended in patients with large direct hernias (M3-EHS classification) undergoing TAPP or TEP to reduce recurrence risk.

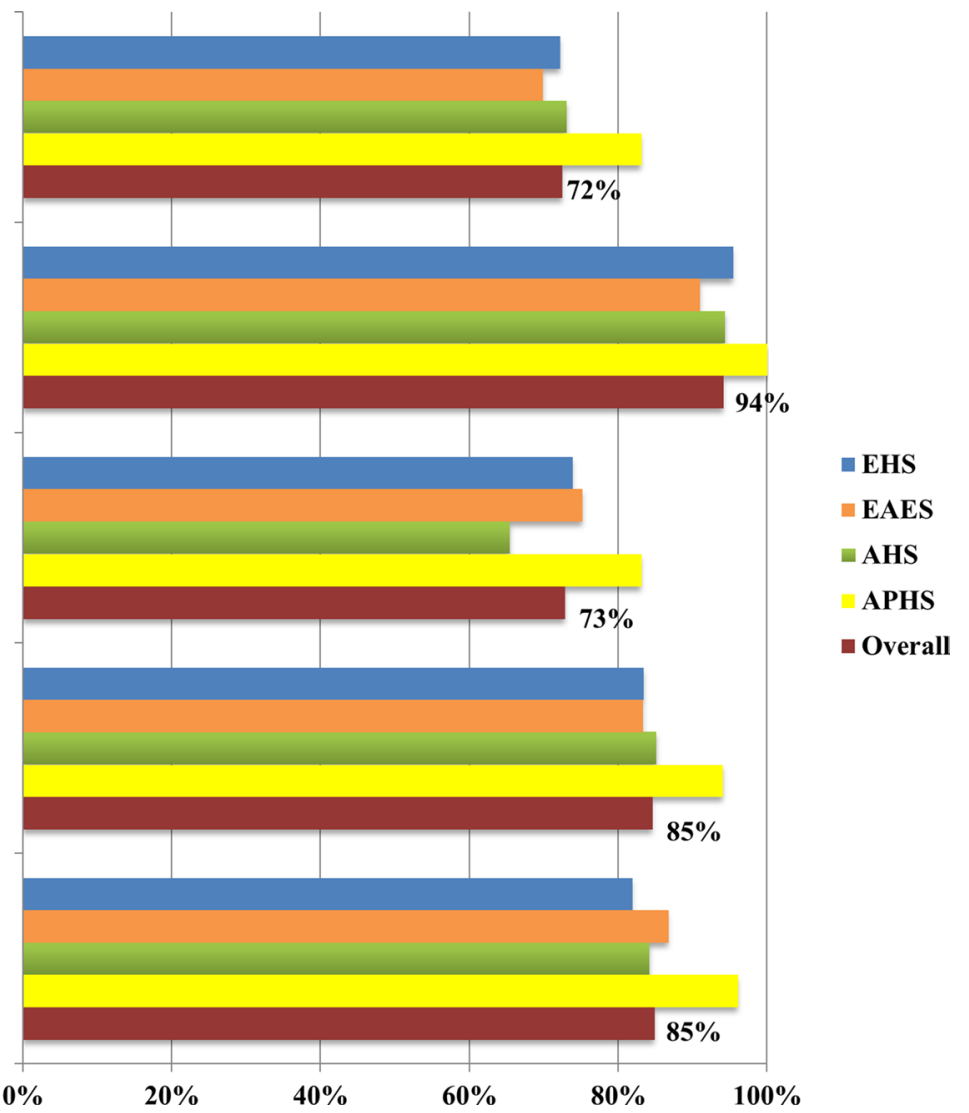

Fig. 6 Level of consensus for each statement and recommendation on Laparo-endoscopic groin hernia repair

it is recommended that the choice of the technique should be based on the surgeon's skills, education, and experience (LoE: moderate; LoC: 94\%).

In almost all cases, mesh fixation in TEP is unnecessary. In both TAPP and TEP it is recommended to fix the mesh in large direct hernias (M3-EHS classification) to reduce recurrence risk (LoE: very low; LoC: $85 \%$ ).

It is recommended that the contra-lateral groin be inspected at the time of TAPP repair. If a contra-lateral inguinal hernia is found at the time of surgery and prior informed consent was obtained, repair is recommended (LoE: very low; LoC: 85\%) [87, 88].

\section{Bilateral, femoral and incarcerated hernias}

Consensus was reached on all recommendations on 'Bilateral, Femoral, and Incarcerated Hernias' (Fig. 7).

Primary bilateral inguinal hernias are recommended to be repaired laparo-endoscopically (LoE: low; LoC: 91\%).
There is discussion concerning the laparo-endoscopic management of potential bilateral hernias (occult hernia issue). After patient consent, during TAPP, the contra-lateral side can be inspected. This is not suggested during unilateral TEP repair.

Provided expertise is available, women with groin hernias are suggested to undergo timely laparo-endoscopic mesh repair in order to decrease chronic pain risk and avoid missing a femoral hernia (LoE: moderate; LoC: 77\%) [89-91].

In the case of elective femoral hernia repair mesh is recommended to be used (LoE: low; LoC: 92\%) [92, 93].

Risk factors for incarceration/strangulation include female gender, femoral hernia presence, and a history of hospitalization related to groin hernia [28, 94-97]. It is suggested that treatment of emergencies is tailored according to patient- and hernia-related factors, local expertise, and resources. Monofilamental large pore polypropylene meshbased repair is suggested in emergent groin hernia surgery with a clean or clean-contaminated surgical field (LoE: low; LoC: $73 \%)[98,99]$. 
30. (R) Laparo-endoscopic repair is recommended for the repair of primary bilateral inguinal hernias provided surgical expertise, cognisent of patient/surgeon/local resource suitability to the surgical approach is available.

31. (R) Provided that expertise is available, women with groin hernias are recommended to undergo laparoendoscopic repair with mesh implantation.

32. (R) Mesh is recommended to be used in elective femoral hernia repairs.

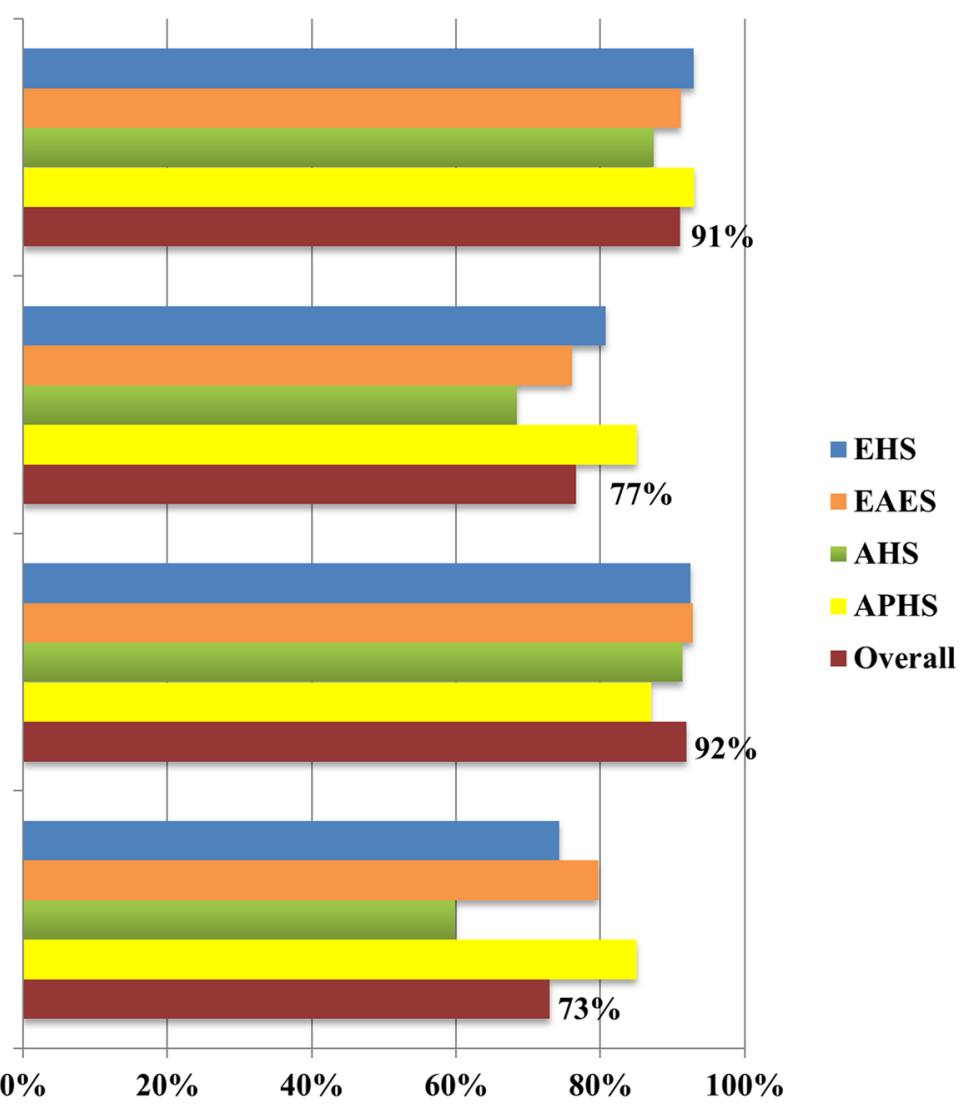

33. (R) Monofilamental large pore polyproplene meshbased repair is suggested in emergent groin hernia surgery with a clean or clean-contaminated surgical field.

$\begin{array}{llllll}0 \% & 20 \% & 40 \% & 60 \% & 80 \% & 100 \%\end{array}$

Fig. 7 Level of consensus for each recommendation on Bilateral, femoral and incarcerated hernias

\section{Outcomes}

Consensus was reached on five of the six recommendations concerning 'Outcomes' (Fig. 8). On the recommendation about immediate re-operation in patients with immediate postoperative pain, there was no agreement (LoE: very low; LoC: $59 \%$ ).

After groin hernia repair an early return to normal activities can be safely recommended (LoE: low; LoC: $83 \%$ ) [100].

Chronic postoperative inguinal pain (CPIP) is a serious complication affecting $10-12 \%$ of inguinal hernia repair patients [101-103]. It is defined as bothersome moderate pain impacting daily activities lasting at least 3 months postoperatively [104]. CPIP risk factors include young age, female gender, high pre-operative pain, early high postoperative pain, recurrent hernia and open repair [7, $105]$.

It is suggested that CPIP management is performed by multidisciplinary teams (LoE: low; LoC: 94\%) [106]. It is also suggested that CPIP is managed by a combination of pharmacological and interventional measures. If this is unsuccessful, management should be followed by, in selected cases, (triple) neurectomy and (in selected cases) mesh removal [107].

Recurrence rates after inguinal hernia repair can be as high as $15 \%$ [108]. For recurrent hernias after failed anterior tissue or mesh repair, posterior repair is recommended (LoE: moderate; LoC: 91\%). If recurrence occurs after a posterior repair, an anterior repair is recommended (LoE: moderate; LoC: $88 \%$ ). After a failed anterior and posterior approach, management by a dedicated hernia surgeon is recommended (LoE: low; LoC: 96\%).

\section{Organization of care}

Consensus was reached on all statements and recommendations concerning the 'Organization of Care' (Fig. 9).

A goal-directed curriculum including review of anatomy, procedure steps, intraoperative decision making and proficiency-based, simulation enhanced technical skills 
34. (R) Patients are recommended to resume normal activities without restrictions as soon as they feel comfortable.

35. (R) Immediate severe/excruciating postoperative pain raises the possibility of vascular or nerve injury. Early reoperation on the same day is suggested to either exclude or manage these complications.

36. (R) A multidisciplinary team is suggested to manage chronic pain patients. Pharmacologic and interventional measures - including diagnostic and therapeutic nerve blocks-should continue for a minimum of three months.

37. (R) Laparo-endoscopic recurrent inguinal hernia repair is recommended after failed anterior tissue or Lichtenstein repair.

38. (R) Anterior repair is recommended after a failed posterior repair.

39. (R) An expert hernia surgeon should repair a recurrent inguinal hernia after a failed anterior and posterior repair The choice of technique depends on patient- and surgeon-specific factors.

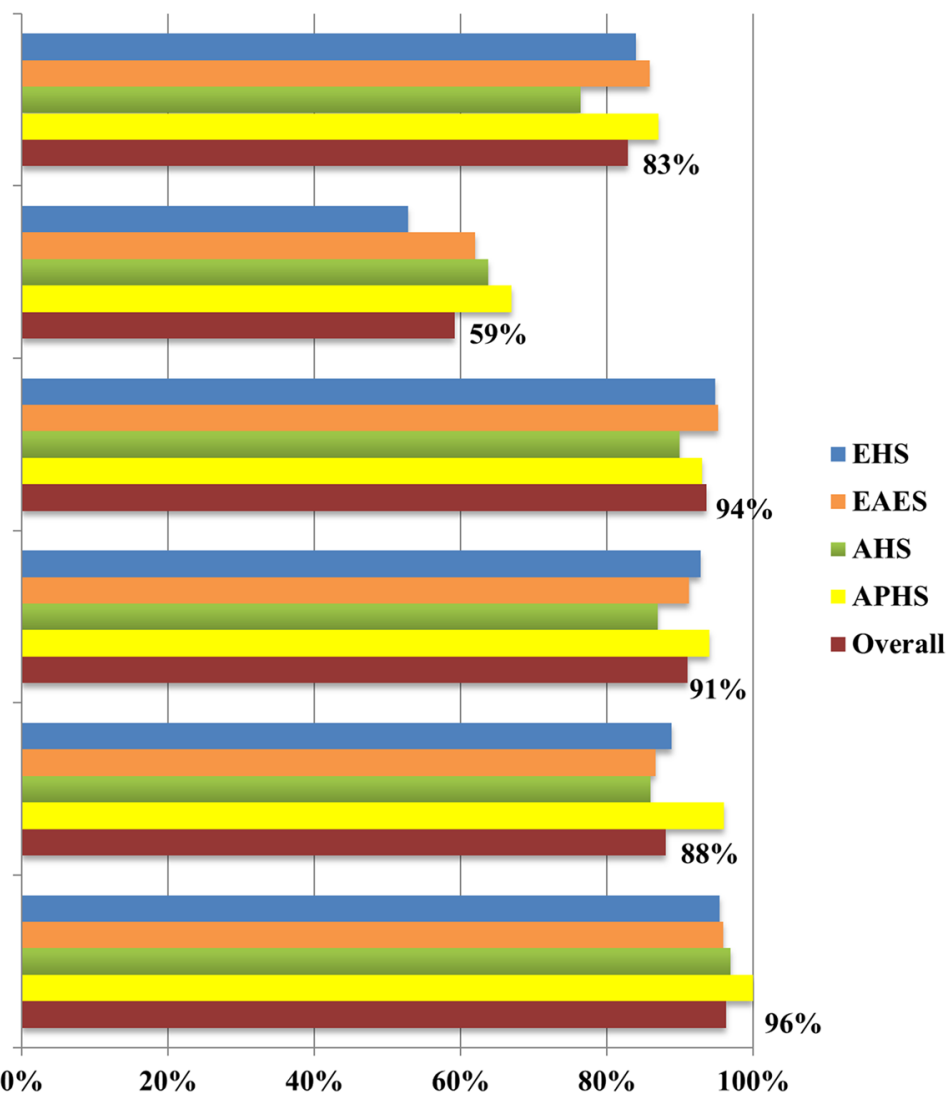

Fig. 8 Level of consensus for each recommendation on Outcomes

training should be available to trainees whenever possible (LoE: moderate; LoC: 97\%) [109].

In order for centers and surgeons to be certified as either a hernia center or a hernia specialist, minimal requirements on numbers of operations, follow-up and quality control should be met (LoE: very low; LoC: 85\%) [110].

The development and implementation of national groin hernia registries in every country is suggested (LoE: low; LoC: $90 \%$ ). They should include long-term patient followup data and account for local healthcare structures.

Due to a substantial lack of access to surgery, inguinal hernia prevalence in low resource settings is too high (LoE: moderate; LoC: 73\%) [111-116]. Dissemination and implementation plans of the guidelines are recommended to be developed by global (HerniaSurge), regional (international societies) and local (national societies/chapters) initiatives through internet websites, social media and smartphone apps (LoE: very low; LoC: 87\%) [117, 118].

It is suggested that in low resource settings the focus is on performing high-volume Lichtenstein repair under local anesthesia using a low-cost mesh (LoE: low; LoC: 87\%) [119].

An overarching plan to improve access to safe inguinal hernia surgery in low resource settings is needed [120]. It is suggested that this plan contains simple guidelines and a sustainability strategy allowing implementation and maintainability, independent of international aid (LoE: low; LoC: $89 \%)$.

\section{Discussion}

This study shows $87 \%$ (range 55-97\%) consensus on the key statements and recommendations from the International Guidelines for Groin Hernia Management. Consensus, defined as more than $70 \%$ agreement among participants, was reached in $87 \%$ (34/39) of recommendations and in $86 \%(6 / 7)$ of statements. No consensus was obtained on one statement and on five recommendations, concerning the categories 'General Aspects' and 'Outcome.' The 
40. (R) A goal-directed curriculum including review of anatomy, procedure steps, intraoperative decision making and proficiency based, simulation enhanced technical skills training should be available to trainees whenever possible.

41. (S) In order for centers and surgeons to be certified as either a hernia center or a hernia specialist, minimal requirements on numbers of operations, follow-up and quality control should be met.

42. (R) Countries or regions are suggested to develop and implement registries with long-term follow-up for groin hernia patients.

43. (R) HerniaSurge recommends that all countries or regions develop a guidelines dissemination and implementation strategy.

44. (S) Due to a substantial lack of access to surgery, inguinal hernia prevalence in low resource settings is too high.

45. (R) Low resource settings should focus teaching the performance of high volume inguinal hernia repair by a standardized technique (Lichtenstein) under local anesthesia using a low-cost mesh.

46. (R) An overarching plan to improve access to safe inguinal hernia surgery in low resource settings is needed. It is suggested that this plan contains practical guidelines and a strategy which should allow implementation and sustainability.

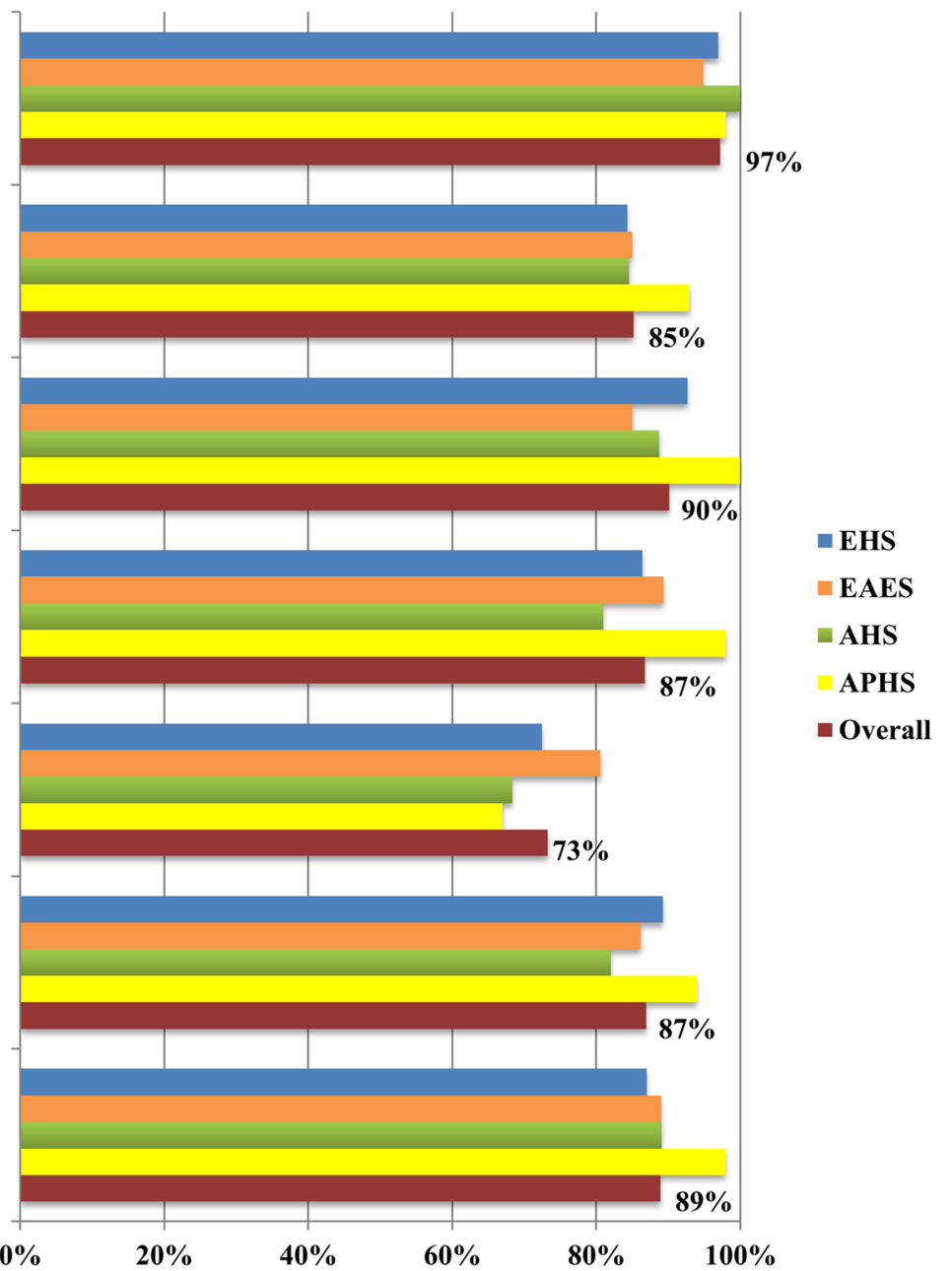

Fig. 9 Level of consensus for each statement and recommendation on Organization of care

high level of agreement by so many surgeons working worldwide is an indication of high support of the content of the international guidelines.

Developing guidelines internationally poses challenges to ensure and monitor the dissemination of the content. Its implementation is subject to local working conditions, availability of resources, local economy, cultural differences, diversity in reimbursement systems and differences in logistical capabilities $[121,122]$. The plenary consensus conferences at four international congresses served as a means to disseminate the content of the international guidelines and to study the level of consensus among the surgical community.

In our study 822 participants cast their votes. This response rate is higher than in a previous consensus conference on groin hernias [8]. The number of participating EHS,
EAES and AHS members was comparable, whereas from the APHS there were only 132 participants. Partly this can be explained by the use of paper questionnaires instead of live voting. A majority of the respondents (540 physicians) completed the web survey. Despite this reasonable number, a higher response rate might have been reached through sending reminders. Optimal use of repetitive emails, internet, and social media might contribute to a higher number of respondents in the future.

In spite of the small number of participating surgeons, assumably a relatively large number of participants are dedicated hernia surgeons. This is reflected by the high number of hernia operations performed per participant annually. The level of experience among the participants was high, with $62.9 \%$ of the participants performing more than 50 repairs annually. The expertise among consensus participants is a strength of this study. 
The average annual number of groin hernia repairs per surgeon was lower for EAES delegates, which can be explained by the fact it is a laparo-endoscopic society and not a society dedicated to hernia surgery alone. Although EAES members are laparo-endoscopic experts, only $43 \%$ favored TAPP or TEP over Lichtenstein $(39,8 \%)$. It is remarkable that representatives of a laparo-endoscopic society favor an open procedure in daily practice.

The preferred laparo-endoscopic method of repair was TEP for all societies. Whereas the mesh plug technique is a popular procedure for inguinal hernia repair in Asia -mainly Japan- [123] the preferred method among the APHS members was a TEP $(35,3 \%)$, possibly explained by the relatively high number of European (39\%) participants at this congress. Specification of the continental origin and the preference of surgical technique can provide clarity on these results. For all hernia societies, there is a potential bias in the diversity of surgeons that voted.

No consensus could be reached on the use of light versus heavy-weight meshes (69\%), superior cost-effectiveness of day-case laparo-endoscopic repair (69\%), omitting prophylactic antibiotics in hernia repair, general or local anesthesia over regional in elderly patients $(55 \%)$ and acute re-operation in case of immediate postoperative pain (59\%). As we did not ask voters for their motivations we can only guess for explanations. Discrepancies can be related to inconclusive (low) evidence, conflicting national protocols, personal experience, cultural differences or financial aspects. Recommendations without consensus give directions for future research.

Our results show that antibiotic prophylaxis remains a controversial issue worldwide. Despite a high level of evidence, no consensus could be reached on omitting antibiotics in open repair $(67 \%)$. Neither consensus was reached for omitting antibiotics in laparo-endoscopic repair (63\%). Differences were distinguished between continents as well: $79 \%$ and $75 \%$ consensus among EHS-members on omitting antibiotic prophylaxis in respectively open and laparo-endoscopic repair, versus only $46 \%$ and $39 \%$ agreement among AHS delegates. The same recommendations were already published in 2009 in the European guidelines for inguinal hernia [6]. Whereas these recommendations seem to have changed daily practice in European countries, implementation in the United States awaits. A possible explanation may be the recommendation of antibiotic prophylaxis in hernia surgery by other guidelines [124]. Furthermore, prophylactic antibiotics are a required indicator and considered a quality measure by Centers for Medicare and Medicaid Services [9]. Medico-legal aspects potentially play a role in the USA.
Conflicting evidence confirms the ambiguity on this topic [125].

Day surgery for groin hernia repair has become increasingly common over the past several decades. Although there was $95 \%$ consensus that groin hernia surgery can be performed in day surgery, there was only $69 \%$ consensus on the cost-effectiveness of day-case laparo-endoscopic repair. This suggests implementation issues with laparo-endoscopic surgery. Financial incentives and judicial prescriptions might play a role since several countries require a hospital stay after certain types of surgery $[126,127]$. The variety in reimbursement policies can be an explanation, but could not be confirmed in this study.

Whereas $81 \%$ of all responders are in favor of the EHS classification system for research and quality purposes, only $69 \%$ of the AHS delegates agreed with this recommendation. This outcome suggests a lower level of acceptance of the EHS classification in the USA. A possible explanation could be the development by European surgeons or discrepancies between the EU and the USA [36, 128].

A limitation of this study is the involvement of only 822 participants. There are over one million specialist surgeons worldwide [129]. The involvement of only a limited number of participants in this consensus study should be critically analyzed.

Lack of a formal consensus conference method can be considered another limitation. Despite the widespread utility of consensus methods, guidelines for conducting consensus studies are lacking [130]. Existing formal consensus methods often synthesize the best available evidence or reflect the opinion of a small number of experts [131-137]. This introduces a bias of highly present knowledge, whereas in the general surgical community other ideas prevail. Modified consensus development conferences with the involvement of the general community have been initiated before, but were limited to Europe only [138], conducted online [139] or had a limited number of participants [6]. The consensus conferences of this study introduce a new research method involving the general surgical community.

A third limitation of this study was the dependency on the logistic circumstances, such as the location and timing of congresses, the conference program, and participation of congress organizations to host the plenary consensus meetings. All consensus conferences needed to be hosted shortly after the online publication of the draft guidelines to facilitate participants with access to background information. Conducting an online consensus study only would limit time and costs. However, 
organizing face-to-face consensus conferences creates more awareness and promotes implementation of the new guideline.

The literature review deadline was July 2015 and new studies were published after this date. This can be considered a limitation because outcomes of new studies have consequences for statements and recommendations. The necessity of updating will always be the case in writing guidelines and consensus development processes.

Lastly, organizing consensus conferences will always require an investment of time and money. Many countries around the world do not have the resources, either in expertise or financially, that are needed. Therefore, it can be argued that the development of international guidelines and global consensus benefits health professionals and patients all around the globe.

\section{Conclusion}

The consensus conferences showed $87 \%$ consensus on the key statements and recommendations of the first International Guidelines for Groin Hernia Management. No consensus was reached on the use of light versus heavyweight meshes (69\%), superior cost-effectiveness of daycase laparo-endoscopic repair (69\%), omitting prophylactic antibiotics in hernia repair, general or local versus regional anesthesia in elderly patients (55\%) and re-operation in case of immediate postoperative pain (59\%). Relevant understanding can be obtained about acceptability of the recommendations and the guideline. The outcomes of this study provide a solid basis for standardizing the care path of patients with groin hernias and identifying future research questions.

Acknowledgements The members of the HerniaSurge group are as follows: Theo Aufenacker, Rijnstate Hospital, Arnhem, the Netherlands; Fredrik Berrevoet, Ghent University Hospital, Ghent, Belgium; Julia Bingener, Mayo Clinic, Rochester, Minnesota; Thue Bisgaard, University of Copenhagen, Copenhagen, Denmark; Reinhard Bittner, Marienhospital Stuttgart, Stuttgart, Germany; Kamil Bury, Medical University of Gdańsk, Gdańsk, Poland; Giampiero Campanelli, University of Insubria, Gruppo Ospedaliero San Donato, Milan, Italy; David Chen, Lichtenstein Amid Hernia Clinic at UCLA, Santa Monica, United States; Pradeep Chowbey, Max Superspeciality Hospital, New Delhi, India; Joachim Conze, Hernienzentrum, Munich, Germany; Diego Cuccurullo, A.O. Dei Colli Monaldi Hospital Naples, Naples, Italy; Andrew De Beaux, Royal Infirmary of Edinburgh, Edinburgh, United Kingdom; Hasan
Eker, University Medical Center Amsterdam, Amsterdam, The Netherlands; Robert Fitzgibbons, Creighton University School of Medicine, Omaha, United States; Rene Fortelny, Wilhelminenspital, Vienna, Austria; Jean Francois Gillion, Hôpital Privé d'Antony, Antony, France; Baukje Van den Heuvel, University Medical Center Amsterdam, Amsterdam, The Netherlands; Lars Jorgensen, Bispebjerg Hospital, University of Copenhagen, Copenhagen, Denmark; Uwe Klinge, University Hospital at the RWTH Aachen, Aachen, Germany; Ferdinand Köckerling, Vivantes Klinikum Spandau; Jan Kukleta, Klinik im Park, Zurich, Switzerland; Ibrahima Konate, University Gaston Berger, Saint Louis, Senegal; Liong Liem, University Medical Center Utrecht, Utrecht, The Netherlands; Davide Lomanto, National University Hospital, Singapore, Singapore; Maarten Loos, Maxima Medical Center, Veldhoven, The Netherlands; Manuel Lopez-Cano, Hospital Universitari Vall d'Hebron, Barcelona, Spain; Marc Miserez, University Hospitals Leuven, Leuven, Belgium; Mahesh Misra, All India Institute of Medical Sciences, New Delhi, India; Agneta Montgomery, Skåne University Hospital, Malmö, Sweden; Salvador Morales-Conde, University Hospital Virgen del Rocío, Seville, Spain; Filip Muysoms, Maria Middelares Hospital, Ghent, Belgium; Henning Niebuhr, Hansechirurgie, Niebuhr Marleschki \& Partner, Hamburg, Germany; Par Nordin, Umeå University, Umeå, Sweden; Maciej Pawlak, Medical University of Gdańsk, Gdańsk, Poland; Gabrielle Van Ramshorst, University Medical Center Amsterdam, Amsterdam, The Netherlands; Wolfgang Reinpold, Hamburg University Hospital, Hamburg, Germany; David Sanders, North Devon District Hospital, Barnstaple, United Kingdom; Rachid Sani, Université Abdou Moumouni, Niamey, Niger; Nelleke Schouten, University Medical Center Utrecht, Utrecht, The Netherlands; Sam Smedberg, Helsingborg Hospital, Helsingborg, Sweden; Maciej Smietanski, Medical University of Gdansk, Gdańsk, Poland; Rogier Simmermacher, University Medical Center Utrecht, Utrecht, The Netherlands; Hanh Tran, University of Sydney, Sydney, Australia; Arthur Wijsmuller, University Medical Center Amsterdam, Amsterdam, The Netherlands.

Funding For all authors none were declared.

\section{Compliance with ethical standards}

Disclosures Nadine van Veenendaal, Maarten Simons, and Sathien Tumtavitikul have no conflicts of interest or financial ties to close. William Hope has no conflicts of interest related to article, but received honorariums from CR Bard and WL Gore for consulting and research support. Jaap Bonjer received grants and personal fees from Medtronic, Johnson\&Johnson, Olympus, Applied Medical, and Stryker, outside the submitted work.

\section{Appendix}

See Table 2 
Table 2 Key statements and recommendations from the International guidelines on groin hernia management

$\mathrm{Nr}$ Statement or rec- Content

Level of evidence Strength of recommendation ommendation

1 Recommendation Clinical examination alone is recommended for confirming the diagno- Low sis of an evident groin hernia

2 Recommendation Acquired, surgical and perioperative risk factors are recommended to be strongly considered since they are potentially modifiable and can influence the type of repair performed

3 Recommendation Use of the EHS classification system for inguinal hernias is suggested Low for the purposes of performing research, tailoring treatments and performing quality audits

4 Statement Although most patients will develop symptoms and need surgery, watchful waiting for minimal or asymptomatic inguinal hernias is safe since the risk of hernia complications is low. Management decision is made between the surgeon and patient

5 Recommendation Discussions with patients about timing of hernia repair are recommended to involve attention to social environment, occupation and overall health. The lower morbidity of elective surgery has to be weighed against the higher morbidity of emergency surgery

6 Recommendation Since a generally accepted technique, suitable for all inguinal hernias, does not exist, it is recommended that surgeons/surgical services provide both an anterior and a posterior approach option

7 Recommendation It is recommended that surgeons tailor treatments based on expertise, local/national resources, and patient- and hernia-related factors

8 Recommendation A mesh-based repair technique is recommended for patients with inguinal hernias

9 Recommendation Hernia surgeons are recommended to be aware of the clinical characteristics of the meshes they use

10 Statement Use of so-called light weight meshes in inguinal hernia surgery (open and laparo-endoscopic) may have some short-term benefits (reduced postoperative pain and shorter convalescence)

11 Recommendation Day surgery is recommended for the majority of groin hernia patients provided adequate aftercare is organized

12 Recommendation From a cost-effectiveness perspective, day-case laparo-endoscopic inguinal hernia repair with minimal use of disposables is recommended

13 Recommendation In open mesh repair, administration of antibiotic prophylaxis in average-risk patients in a low-risk environment is not recommended

14 Recommendation In laparo-endoscopic repair, administration of antibiotic prophylaxis in Low average-risk patients in any environment is not recommended

15 Recommendation Local anesthesia is recommended for open repair of reducible inguinal hernias provided surgeons/teams are experienced in local anesthesia use and administering the local anesthetic

16 Recommendation General or local anesthesia is suggested over regional in patients aged 65 and older

17 Recommendation Pre- or perioperative local anesthetic measures like field blocks of the inguinal nerves and/or subfascial/subcutaneous infiltration are recommended in all open groin hernia repairs

18 Recommendation The Shouldice technique has lower recurrence rates than other suture repairs and is recommended in non-mesh inguinal hernia repair

19 Statement The use of open non-mesh repair in specific patients or types (e.g., young males with lateral hernia L1) of inguinal hernia as an acceptable alternative to a Lichtenstein technique requires further studies

20 Statement In open surgery there is insufficient evidence to recommend a preperitoneal mesh repair over Lichtenstein repair. Future research is required

High

Very low

Strong*Upgraded

Very low

Strong*Upgraded

Very low

Strong*Upgraded

Moderate

Strong*Upgraded

Low

Strong*Upgraded

Low

Moderate

Strong

Moderate

Strong

High

Strong

Strong*Upgraded

Strong

Weak

High

Strong

Moderate

Strong*Upgraded

Low

Very low 
Table 2 (continued)

$\mathrm{Nr}$ Statement or rec- Content

Level of evidence Strength of recommendation ommendation

21 Recommendation Despite comparable results, three-dimensional implants (plug-andpatch and bilayer) are not recommended because of the excessive use

Strong*Upgraded of foreign material, the need to enter both the posterior and anterior plane and the additional cost

22 Recommendation Nerve anatomy awareness and recognition during surgery is recommended to reduce the incidence of chronic post-herniorrhaphy pain

23 Recommendation During open surgery, planned prophylactic ilioinguinal nerve resection L is not suggested since it does not reduce chronic pain incidence and it increases postoperative sensory loss

24 Recommendation Pragmatic resection of the ilioinguinal nerve and/or the iliohypogastric Low nerve is recommended if iatrogenic nerve injury occurs or if the nerve(s) interfere(s) with mesh position

25 Statement

TAPP and TEP have similar operative times, overall complication risks, postoperative acute and chronic pain incidence and recurrence rates

26 Recommendation In laparo-endoscopic inguinal hernia repair, TAPP and TEP have comparable outcomes; hence, it is recommended that the choice of the technique should be based on the surgeon's skills, education and experience

27 Recommendation For male patients with primary unilateral inguinal hernia, a laparoendoscopic technique is suggested because of a lower postoperative pain incidence and a reduction in chronic pain incidence, provided that a surgeon with specific expertise and sufficient resources is available. However, there are patient and hernia characteristics that warrant a Lichtenstein as first choice

28 Recommendation It is recommended that the contra-lateral groin be inspected at time of TAPP repair. If a contra-lateral inguinal hernia is found at the time of surgery and prior informed consent was obtained, repair is recommended

29 Recommendation Mesh fixation is recommended in patients with large direct hernias (M3-EHS classification) undergoing TAPP or TEP to reduce recurrence risk

30 Recommendation Laparo-endoscopic repair is recommended for the repair of primary bilateral inguinal hernias provided surgical expertise, cognisent of patient/surgeon/local resource suitability to the surgical approach is available

31 Recommendation Provided that expertise is available, women with groin hernias are recommended to undergo laparo- endoscopic repair with mesh implantation

Very low

Strong*Upgraded

Low

Strong*Upgraded

Moderate Strong*Upgraded

32 Recommendation Mesh is recommended to be used in elective femoral hernia repairs

33 Recommendation Monofilamental large pore polyproplene mesh-based repair is suggested in emergent groin hernia surgery with a clean or clean-contaminated surgical field

34 Recommendation Patients are recommended to resume normal activities without restric- Low

34 Recommendation Patients are recommended to resume normal activities without restric- Low
tions as soon as they feel comfortable

35 Recommendation Immediate severe/excruciating postoperative pain raises the possibility Very low of vascular or nerve injury Early re-operation on the same day is suggested to either exclude or manage these complications

Low

Low

Strong*Upgraded

Weak

Strong*Upgraded

Weak

Weak

36 Recommendation A multidisciplinary team is suggested to manage chronic pain patients. Low Pharmacologic and interventional measures-including diagnostic and therapeutic nerve blocks - should continue for a minimum of three months (minimum of six months after hernia surgery)

37 Recommendation Laparo-endoscopic recurrent inguinal hernia repair is recommended after failed anterior tissue or Lichtenstein repair

38 Recommendation Anterior repair is recommended after a failed posterior repair
Strong

Moderate Strong 
Table 2 (continued)

$\mathrm{Nr}$ Statement or rec- Content ommendation

Level of evidence Strength of recommendation

39 Recommendation An expert hernia surgeon should repair a recurrent inguinal hernia after a failed anterior and posterior repair. The choice of technique depends on patient- and surgeon-specific factors

40 Recommendation A goal-directed curriculum including review of anatomy, procedure steps, intraoperative decision making and proficiency-based, simulation enhanced technical skills training should be available to trainees whenever possible

41 Statement

In order for centers and surgeons to be certified as either a hernia center or a hernia specialist, minimal requirements on numbers of operations, follow-up and quality control should be met

42 Recommendation Countries or regions are suggested to develop and implement registries with long-term follow-up for groin hernia patients

43 Recommendation HerniaSurge recommends that all countries or regions develop a guidelines dissemination and implementation strategy

Low Strong*Upgraded

Moderate Strong

(1)

Very low

Low Weak

Very low Strong

Moderate

lence in low resource settings is too high

45 Recommendation Low resource settings should focus teaching the performance of highvolume inguinal hernia repair by a standardized technique (Lichtenstein) under local anesthesia using a low-cost mesh

46 Recommendation An overarching plan to improve access to safe inguinal hernia surgery in low resource settings is needed. It is suggested that this plan contains practical guidelines and a strategy which should allow implementation and sustainability

\section{References}

1. Beard JH, Ohene-Yeboah M, Devries CR, Schecter WP (2015) Hernia and hydrocele. In: Debas HT, Donkor P, Gawande A, Jamison DT, Kruk ME, Mock CN. Essential Surgery: Disease Control Priorities, 3rd edn, vol 1. Washington (DC): The International Bank for Reconstruction and Development/The World Bank; 2015 Apr. Chapter 9.

2. Meara JG, Leather AJ, Hagander L, Alkire BC, Alonso N, Ameh EA, Bickler SW, Conteh L, Dare AJ, Davies J, Mérisier ED, El-Halabi S, Farmer PE, Gawande A, Gillies R, Greenberg SL, Grimes CE, Gruen RL, Ismail EA, Kamara TB, Lavy C, Lundeg G, Mkandawire NC, Raykar NP, Riesel JN, Rodas E, Rose J, Roy N, Shrime MG, Sullivan R, Verguet S, Watters D, Weiser TG, Wilson IH, Yamey G, Yip W (2015) Global surgery 2030: evidence and solutions for achieving health, welfare, and economic development. Lancet 386(9993):569-624

3. Price R, Makasa E, Hollands M (2015) World Health Assembly Resolution WHA68.15: "strengthening emergency and essential surgical care and anesthesia as a component of universal health coverage" - addressing the public health gaps arising from lack of safe, affordable and accessible surgical and anesthetic services. World J Surg 39(9):2115-2125

4. Meara JG, Hagander L, Leather AJ (2014) Surgery and global health: a Lancet commission. Lancet 383(9911):12-13

5. Botman M, Meester RJ, Voorhoeve R, Mothes H, Henry JA, Cotton MH, Lane RH, Jani PG, Heij HA, Ismail EA (2015) The Amsterdam declaration on essential surgical care. World J Surg 39(6):1335-1340

6. Simons MP, Aufenacker T, Bay-Nielsen M, Bouillot JL, Campanelli G, Conze J, de Lange D, Fortelny R, Heikkinen T, Kingsnorth A, Kukleta J, Morales-Conde S, Nordin P, Schumpelick V, Smedberg S, Smietanski M, Weber G, Miserez M (2009)
European Hernia Society guidelines on the treatment of inguinal hernia in adult patients. Hernia 13:343-403

7. Bittner R, Arregui ME, Bisgaard T, Dudai M, Ferzli GS, Fitzgibbons RJ, Fortelny RH, Klinge U, Kockerling F, Kuhry E, Kukleta J, Lomanto D, Misra MC, Montgomery A, Morales-Conde S, Reinpold W, Rosenberg J, Sauerland S, Schug-Pass C, Singh K, Timoney M, Weyhe D, Chowbey P (2011) Guidelines for laparoscopic (TAPP) and endoscopic (TEP) treatment of inguinal hernia [International Endohernia Society (IEHS)]. Surg Endosc 25(9):2773-2843

8. Poelman MM, van den Heuvel B, Deelder JD, Abis GS, Beudeker N, Bittner RR, Campanelli G, van Dam D, Dwars BJ, Eker HH, Fingerhut A, Khatkov I, Koeckerling F, Kukleta JF, Miserez M, Montgomery A, Munoz Brands RM, Morales Conde S, Muysoms FE, Soltes M, Tromp W, Yavuz Y, Bonjer HJ (2013) EAES Consensus Development Conference on endoscopic repair of groin hernias. Surg Endosc 27(10):3505-3519

9. HerniaSurge Group (2018) International guidelines for groin hernia management. Hernia 22(1):1-165

10. Atkins D, Eccles M, Flottorp S, Guyatt GH, Henry D, Hill S, Liberati A, O'Connell D, Oxman AD, Phillips B, Schünemann H, Edejer TT, Vist GE, Williams JW Jr, GRADE Working Group (2004) Systems for grading the quality of evidence and the strength of recommendations I: critical appraisal of existing approaches The GRADE Working Group. BMC Health Serv Res 4(1):38

11. Goldet G, Howick J (2013) Understanding GRADE: an introduction. J Evid Based Med 6(1):50-54

12. Campanelli G (2018) Endorsement of the Herniasurge guidelines by the European Hernia Society. Hernia 22(1):169

13. Carbonell AM (2018) Endorsement of the HerniaSurge guidelines by the Americas Hernia Society. Hernia 22(1):171 
14. Sharma A (2018) Endorsement of the HerniaSurge guidelines by the Asia Pacific Hernia Society. Hernia 22(1):173

15. Sani R (2018) Endorsement of the HerniaSurge guidelines by the Afro Middle East Hernia Society. Hernia 22(1):175

16. Tran H (2018) Endorsement of the HerniaSurge guidelines by the Australasian Hernia Society. Hernia 22(1):177

17. Bittner R, Köckerling F (2018) Endorsement of the HerniaSurge guidelines by the International Endohernia Society. Hernia 22(1):179

18. Targarona EM (2018) Endorsement of the HerniaSurge guidelines by the European Association of Endoscopic Surgery. Hernia 22(1): 181

19. Phillips B, Ball C, Sackett D, Badenoch D, Straus S, Haynes BDM (2001) Oxford centre for evidence-based medicine - Levels of evidence. $\mathrm{http}: / / \mathrm{www} . \mathrm{cebm}$. net/index.aspx?o=1025. Accessed 10 Mar 2019

20. SIGN 50 (2019) A guideline developer's handbook. https://www. sign.ac.uk/sign-50.html. Accessed 10 March 2019

21. Brouwers MC, Kho ME, Browman GP, Burgers JS, Cluzeau F, Feder G, Fervers B, Graham ID, Grimshaw J, Hanna SE, Littlejohns P, Makarski J, Zitzelsberger L, AGREE Next Steps Consortium (2010) AGREE II: advancing guideline development, reporting and evaluation in health care. CMAJ 182(18):E839-E842

22. Van den Berg JC, de Valois JC, Go PM, Rosenbusch G (1999) Detection of groin hernia with physical examination, ultrasound, and MRI compared with laparoscopic findings. Invest Radiol 34(12):739-743

23. Garvey JFW (2012) Computed tomography scan diagnosis of occult groin hernia. Hernia 16(3):307-314

24. Akin ML, Karakaya M, Batkin A, Nogay A (1997) Prevalence of inguinal hernia in otherwise healthy males of 20 to 22 years of age. J R Army Med Corps 143(2):101-102

25. Liem MS, van der Graaf Y, Zwart RC, Geurts I, van Vroonhoven TJ (1997) Risk factors for inguinal hernia in women: a case-control study. The coala trial group. Am J Epidemiol 146(9):721-726

26. Burcharth J, Pedersen M, Bisgaard T, Pedersen C, Rosenberg J (2013) Nationwide prevalence of groin hernia repair. PLoS ONE 8(1):e5436

27. Van Wessem KJP, Simons MP, Plaisier PW (2003) The etiology of indirect inguinal hernias: congenital and/or acquired? Hernia 7(2):76-79. https://doi.org/10.1007/s10029-002-0108-7

28. Ruhl CE, Everhart JE (2007) Risk factors for inguinal hernia among adults in the US population. Am J Epidemiol 165(10):1154-1161

29. Quintas ML, Rodrigues CJ, Yoo JH, Junior RAJ (2000) Age related changes in the elastic fiber system of the interfoveolar ligament. Rev Hosp Clin Fac Med Sao Paulo 55(3):83-86

30. Nilsson H, Stranne J, Stattin P, Nordin P (2014) Incidence of groin hernia repair after radical prostatectomy: a populationbased nationwide study. Ann Surg 259(6):1223-1227

31. Stranne J, Johansson E, Nilsson A, Bill-Axelson A, Carlsson S, Holmberg L, Johansson JE, Nyberg T, Ruutu M, Wiklund NP, Steineck G (2010) Inguinal hernia after radical prostatectomy for prostate cancer: results from a randomized setting and a nonrandomized setting. Eur Urol 58(5):719-726

32. Lodding P, Bergdahl C, Nyberg M, Pileblad E, Stranne J, Hugosson J (2001) Inguinal hernia after radical retropubic prostatectomy for prostate cancer: a study of incidence and risk factors in comparison to no operation and lymphadenectomy. J Urol 166(3):964-967

33. Ichioka K, Kohei N, Yoshimura K, Arai Y, Terai A (2007) Impact of retraction of vas deferens in postradical prostatectomy inguinal hernia. Urology 70(3):511-514
34. Rosemar A, Angerås U, Rosengren A, Nordin P (2010) Effect of body mass index on groin hernia surgery. Ann Surg 252(2):397-401

35. Rosemar A, Angerås U, Rosengren A (2008) Body mass index and groin hernia: a 34-year follow-up study in Swedish men. Ann Surg 247(6):1064-1068

36. Miserez M, Alexandre JH, Campanelli G, Corcione F, Cuccurullo D, Pascual MH, Hoeferlin A, Kingsnorth AN, Mandala V, Palot JP, Schumpelick V, Simmermacher RK, Stoppa R, Flament JB (2007) The European hernia society groin hernia classification: simple and easy to remember. Hernia 11(2):113-116

37. Fitzgibbons RJ, Giobbie-Hurder A, Gibbs JO, Dunlop DD, Reda DJ, McCarthy M Jr, Neumayer LA, Barkun JS, Hoehn JL, Murphy JT, Sarosi GA Jr, Syme WC, Thompson JS, Wang J, Jonasson O (2006) Watchful waiting vs repair of inguinal hernia in minimally symptomatic men: a randomized clinical trial. JAMA 295(3):285-292

38. O'Dwyer PJ, Norrie J, Alani A, Walker A, Duffy F, Horgan P (2006) Observation or operation for patients with an asymptomatic inguinal hernia: a randomized clinical trial. Ann Surg 244(2):167-173

39. Van den Heuvel B, Dwars BJ, Klassen DR, Bonjer HJ (2011) Is surgical repair of an asymptomatic groin hernia appropriate? A review. Hernia 15(3):251-259

40. INCA Trialists Collaboration (2011) Operation compared with watchful waiting in elderly male inguinal hernia patients: a review and data analysis. J Am Coll Surg 212(2):251

41. Morales-Conde S, Socas M, Fingerhut A (2012) Endoscopic surgeons' preferences for inguinal hernia repair: TEP, TAPP, or OPEN. Surg Endosc 26(9):2639-2643

42. Schmedt CG, Sauerland S, Bittner R (2005) Comparison of endoscopic procedures vs Lichtenstein and other open mesh techniques for inguinal hernia repair: a meta-analysis of randomized controlled trials. Surg Endosc 19(2):188-199

43. Hamza Y, Gabr E, Hammadi H, Khalil R (2010) Four-arm randomized trial comparing laparoscopic and open hernia repairs. Int J Surg 8(1):25-28

44. Butler RE, Burke R, Schneider JJ, Brar H, Lucha PA (2007) The economic impact of laparoscopic inguinal hernia repair: results of a double-blinded, prospective, randomized trial. Surg Endosc 21(3):387-390

45. Heikkinen TJ, Haukipuro K, Koivukangas P, Hulkko A (1998) A prospective randomized outcome and cost comparison of totally extraperitoneal endoscopic hernioplasty versus Lichtenstein hernia operation among employed patients. Surg Laparosc Endosc 8(5):338-344

46. Gokalp A, Inal M, Maralcan G, Baskonus I (2003) A prospective randomized study of Lichtenstein open tension-free versus laparoscopic totally extraperitoneal techniques for inguinal hernia repair. Acta Chir Belg 103(5):502-506

47. Lau H, Patil NG, Yuen WK (2006) Day-case endoscopic totally extraperitoneal inguinal hernioplasty versus open Lichtenstein hernioplasty for unilateral primary inguinal hernia in males: a randomized trial. Surg Endosc 20(1):76-81

48. Eklund A, Montgomery A, Bergkvist L, Rudberg C (2010) Chronic pain 5 years after randomized comparison of laparoscopic and Lichtenstein inguinal hernia repair. Br J Surg 97(4):600-608

49. Eklund A, Carlsson P, Rosenblad A, Montgomery A, Bergkvist L, Rudberg C (2010) Long-term cost-minimization analysis comparing laparoscopic with open (Lichtenstein) inguinal hernia repair. Br J Surg 97(5):765-771

50. Dahlstrand U, Sandblom G, Ljungdahl M, Wollert S, Gunnarsson U (2013) TEP under general anesthesia is superior to Lichtenstein under local anesthesia in terms of pain 6 weeks after 
surgery: results from a randomized clinical trial. Surg Endosc Other Interv Tech 27:3632-3638

51. Dhankhar DS, Sharma N, Mishra T, Kaur N, Singh S, Gupta S (2014) Totally extraperitoneal repair under general anesthesia versus Lichtenstein repair under local anesthesia for unilateral inguinal hernia: a prospective randomized controlled trial. Surg Endosc 28(3):996-1002

52. Koninger J, Redecke J, Butters M (2004) Chronic pain after hernia repair: a randomized trial comparing Shouldice Lichtenstein and TAPP. Langenbecks Arch Surg 389(5):361-365

53. Butters M, Redecke J, Kninger J (2007) Long-term results of a randomized clinical trial of Shouldice, Lichtenstein and transabdominal preperitoneal hernia repairs. Br J Surg 94(5):562-565

54. Kockerling F, Stechemesser B, Hukauf M, Kuthe A, Schug-Pass C (2015) TEP versus Lichtenstein: which technique is better for the repair of primary unilateral inguinal hernias in men? Surg Endosc 30(8):3304-3313

55. Voyles CR, Hamilton BJ, Johnson WD, Kano N (2002) Metaanalysis of laparoscopic inguinal hernia trials favors open hernia repair with preperitoneal mesh prosthesis. Am J Surg 184:6-10

56. Amato B, Moja L, Panico S, Persico G, Rispoli C, Rocco N, Moschetti I (2009) Shouldice technique versus other open techniques for inguinal hernia repair. Cochrane Database Syst Rev 7(4):CD001543

57. Majholm B, Engbæk J, Bartholdy J, Oerding H, Ahlburg P, Ulrik AM, Bill L, Langfrits CS, Møller AM (2012) Is day surgery safe? A Danish multicentre study of morbidity after 57,709 day surgery procedures. Acta Anaesthesiol Scand 56(3):323-331

58. McCormack K, Scott NW, Go PM, Ross S, Grant AM (2003) Laparoscopic techniques versus open techniques for inguinal hernia repair. Cochrane Database Syst Rev 1:CD01785

59. Cheek CM, Black NA, Devlin HB, Kingsnorth AN, Taylor RS, Watkin DF (1998) Groin hernia surgery: a systematic review. Ann R Coll Surg Engl 80(Suppl 1):S1-80

60. Reece-Smith AM, Maggio AQ, Tang TY, Walsh SR (2009) Local anaesthetic vs. general anaesthetic for inguinal hernia repair: systematic review and meta-analysis. Int J Clin Pract 63(12):1739-1742

61. Jensen P, Mikkelsen T, Kehlet H (2002) Postherniorrhaphy urinary retention - effect of local, regional, and general anesthesia: a review. Reg Anesth Pain Med 27(6):612-617

62. Kehlet H, Aasvang E (2005) Groin hernia repair: anesthesia. World J Surg 29(8):1058-1061

63. Callesen $T$ (2003) Inguinal hernia repair: anaesthesia, pain and convalescence. Dan Med Bull 50(3):203-218

64. Joshi GP, Rawal N, Kehlet H, PROSPECT collaboration, Bonnet F, Camu F, Fischer HB, Neugebauer EA, Schug SA, Simanski CJ (2012) Evidence-based management of postoperative pain in adults undergoing open inguinal hernia surgery. Br J Surg 99(2):168-185

65. Andersen FH, Nielsen K, Kehlet H (2005) Combined ilioinguinal blockade and local infiltration anaesthesia for groin hernia repair-a double-blind randomized study. Br J Anaesth 94:520-523

66. Ding Y, White PF (1995) Post-herniorrhaphy pain in outpatients after pre-incision ilioinguinal-hypogastric nerve block during monitored anaesthesia care. Can J Anaesth 42:12-15

67. Toivonen J, Permi J, Rosenberg PH (2001) Effect of preincisional ilioinguinal and iliohypogastric nerve block on postoperative analgesic requirement in day-surgery patients undergoing herniorrhaphy under spinal anaesthesia. Acta Anaesthesiol Scand 45:603-607

68. Bugedo GJ, Carcamo CR, Mertens RA, Dagnino JA, Munoz HR (1990) Preoperative percutaneous ilioinguinal and iliohypogastric nerve block with $0.5 \%$ bupivacaine for post-herniorrhaphy pain management in adults. Reg Anesth 15:130-133
69. O'Hanlon JJ, McCleane G, Muldoon T (1996) Preoperative application of piroxicam gel compared to a local anaesthetic field block for postoperative analgesia. Acta Anaesthesiol Scand 40:715-718

70. Willaert W, Berrevoet F, De Bacquer D, Rogiers X, Troisi R (2009) Open preperitoneal techniques versus Lichtenstein repair for inguinal hernia. Cochrane Database Syst Rev 4:1-28

71. Sajid MS, Craciunas L, Singh KK, Sains P, Baig MK (2013) Open transinguinal preperitoneal mesh repair of inguinal hernia: a targeted systematic review and meta-analysis of published randomized controlled trials. Gastroenterol Rep 1:127-137

72. Zhao G, Gao P, Ma B, Tian J, Yang K (2009) Open mesh techniques for inguinal hernia repair: a meta-analysis of randomized controlled trials. Ann Surg 250:35-42

73. Li J, Ji Z, Li Y (2012) Comparison of mesh-plug and Lichtenstein for inguinal hernia repair: a meta-analysis of randomized controlled trials. Hernia 16:541-548

74. Nienhuijs SW, Rosman C (2015) Long-term outcome after randomizing prolene hernia system, mesh plug repair and Lichtenstein for inguinal hernia repair. Hernia 19:77-81

75. Droeser RA, Dell-Kuster S, Kurmann A, Rosenthal R, Zuber M, Metzger J, Oertli D, Hamel CT, Frey DM (2014) Long-term follow-up of a randomized controlled trial of Lichtenstein's operation versus mesh plug repair for inguinal hernia. Ann Surg 259:966-972

76. Li J, Ji Z, Li Y (2014) The comparison of self-gripping mesh and sutured mesh in open inguinal hernia repair: the results of meta-analysis. Ann Surg 259(6):1080-1085

77. Pierides G, Scheinin T, Remes V, Hermunen K, Vironen J (2012) Randomized comparison of self-fixating and sutured mesh in open inguinal hernia repair. Br J Surg 99:630-636

78. Memon MA, Cooper NJ, Memon B, Memon MI, Abrams KR (2003) Meta-analysis of randomized clinical trials comparing open and laparoscopic inguinal hernia repair. Br J Surg 90:1479-1492

79. Weiser H, Klinge B (2000) Endoskopische operationstechniken. Erfahrungen und besonderheiten-leistenhernie. Viszeralchirurgie 35(3):316-320

80. McCormack K, Wake BL, Fraser C, Vale L, Perez J, Grant A (2005) Transabdominal pre-peritoneal (TAPP) versus totally extraperitoneal (TEP) laparoscopic techniques for inguinal hernia repair: a systematic review. Hernia 9(2):109-114

81. Tolver MA, Rosenberg J, Bisgaard T (2012) Early pain after laparoscopic inguinal hernia repair. a qualitative systematic review. Acta Anaesthesiol Scand 56:549-557

82. O'Reilly EA, Burke JP, O'Connell PR (2012) A meta-analysis of surgical morbidity and recurrence after laparoscopic and open repair of primary unilateral inguinal hernia. Ann Surg 255(5):846-853

83. Bracale U, Melillo P, Pignata G, Di Salvo E, Rovani M, Merola G, Pecchia L (2012) Which is the best laparoscopic approach for inguinal hernia repair: TEP or TAPP? A systematic review of the literature with a network meta-analysis. Surg Endosc 26:3355-3366

84. Antoniou SA, Antoniou GA, Bartsch DK, Fendrich V, Koch OO, Pointner R, Granderath FA (2013) Transabdominal preperitoneal versus totally extraperitoneal repair of inguinal hernia: a metaanalysis of randomized studies. Am J Surg 206:245-252

85. Wei FX, Zhang YC, Han W, Zhang YL, Shao Y, Ni R (2015) Transabdominal Preperitoneal (TAPP) versus totally. Laparosc Endosc Percutan Tech 25(5):375-383

86. McCormack K, Wake B, Perez J (2005) Laparoscopic surgery for inguinal hernia repair: systematic review of effectiveness and economic evaluation. Health Technol Assess 9(1-203):iii-iv

87. Van den Heuvel B, Beudeker N, Van den Broek J, Bogte ADB (2013) The incidence and natural course of occult inguinal 
hernias during TAPP repair. Repair is beneficial. Surg Endosc 27:4142-4146

88. Thumbe VKED (2001) To repair or not to repair incidental defects found on laparoscopic repair of groin hernia. Surg Endosc 15:47-49

89. Kark AEKM (2008) Groin hernias in women. Hernia 12(3):267-270

90. Lau H, Patil NGYW (2005) Is endoscopic totally extraperitoneal hernioplasty justified for the repair of groin hernia in female patients? Surg Endosc 19(12):1544-1548

91. Schouten N, Burgmans JP, van Dalen T, Smakman N, Clevers GJ, Davids PH, Verleisdonk EJ, Elias SG, Simmermacher RK (2012) Female 'groin' hernia: totally extraperitoneal (TEP) endoscopic repair seems the most appropriate treatment modality. Hernia 16(4):387-392

92. Andresen K, Bisgaard T, Kehlet H, Wara P, Rosenberg J (2014) Reoperation rates for laparoscopic vs open repair of femoral hernias in Denmark: a nationwide analysis. JAMA Surg 149(8):853-857

93. Bay-Nielsen M, Kehlet H, Strand L, Malmstrøm J, Andersen FH, Wara P, Juul P, Callesen T, Collaboration DHD (2001) Quality assessment of 26,304 herniorrhaphies in Denmark: a prospective nationwide study. Lancet 358(9288):1124-1128

94. Dahlstrand U, Wollert S, Nordin P, Sandblom G, Gunnarsson U (2009) Emergency femoral hernia repair: a study based on a national register. Ann Surg 249(4):672-676

95. Kurt N, Oncel M, Ozkan Z, Bingul S (2003) Risk and outcome of bowel resection in patients with incarcerated groin hernias: retrospective study. World J Surg 27(6):741-743

96. Suppiah A, Gatt M, Barandiaran J, Heng MS, Perry EP (2007) Outcomes of emergency and elective femoral hernia surgery in four district general hospitals: a 4-year study. Hernia 11(6):509-512

97. Alhambra-Rodriguez de Guzmán C, Picazo-Yeste J, TeníasBurillo JM, Moreno-Sanz C (2013) Improved outcomes of incarcerated femoral hernia: a multivariate analysis of predictive factors of bowel ischemia and potential impact on postoperative complications. Am J Surg 205(2):188-193

98. Myers E, Browne KM, Kavanagh DO, Hurley M (2010) Laparoscopic (TEP) versus Lichtenstein inguinal hernia repair: a comparison of quality-of-life outcomes. World J Surg 34(12):3059-3064

99. Atila K, Guler S, Inal A, Sokmen S, Karademir S, Bora S (2010) Prosthetic repair of acutely incarcerated groin hernias: a prospective clinical observational cohort study. Langenbeck's Arch Surg 395(5):563-568

100. Bay-Nielsen M, Thomsen H, Andersen F, Bendix JH, Sørensen OK, Skovgaard N, Kehlet H (2004) Convalescence after inguinal herniorrhaphy. Br J Surg 91(3):362-367

101. Alfieri S, Amid PK, Campanelli G, Izard G, Kehlet H, Wijsmuller AR, Di Miceli D, Doglietto GB (2011) International guidelines for prevention and management of post-operative chronic pain following inguinal hernia surgery. Hernia 15(3):239-249

102. Bay-Nielsen M, Nilsson E, Nordin P, Kehlet H (2004) Chronic pain after open mesh and sutured repair of indirect inguinal hernia in young males. Br J Surg 91(10):1372-1376

103. Nienhuijs SW, Rosman C, Strobbe LJA, Wolff A, Bleichrodt RP (2008) An overview of the features influencing pain after inguinal hernia repair. Int J Surg 6(4):351-356

104. International Association for the Study of Pain (1986) Classification of chronic pain. Descriptions of chronic pain syndromes and definitions of pain terms. Prepared by the International Association for the Study of Pain. Subcomm Taxon Pain Suppl 3:S1-226
105. Bjurstrom MF, Nicol AL, Amid PK, Chen DC (2014) Pain control following inguinal herniorrhaphy: current perspectives. J Pain Res 7:277-290

106. Lange JFM, Kaufmann R, Wijsmuller AR, Pierie JP, Ploeg RJ, Chen DC, Amid PK (2014) An international consensus algorithm for management of chronic postoperative inguinal pain. Hernia 19(1):33-43

107. Alfieri S, Rotondi F, Di Giorgio A, Fumagalli U, Salzano A, Di Miceli D, Ridolfini MP, Sgagari A, Doglietto G, Groin Pain Trial Group (2006) Influence of preservation versus division of ilioinguinal, iliohypogastric, and genital nerves during open mesh herniorrhaphy: prospective multicentric study of chronic pain. Ann Surg 243(4):553-555

108. Neumayer L, Giobbie-Hurder A, Jonasson O, Fitzgibbons R Jr, Dunlop D, Gibbs J, Reda D, Henderson W, Veterans Affairs Cooperative Studies Program (2004) Open mesh versus laparoscopic mesh repair of inguinal hernia. N Engl J Med 350:1819-1827

109. Gurusamy KS, Nagendran M, Toon CD, Davidson BR (2014) Laparoscopic surgical box model training for surgical trainees with limited prior laparoscopic experience. Cochrane Database Syst Rev 1(3):CD010478

110. Köckerling F, Berger D, Jost JO (2014) What is a Certified Hernia Center? The Example of the German Hernia Society and German Society of General and Visceral Surgery. Front Surg 1(July): $1-4$

111. Lofgren J, Makumbi F, Galiwango E, Nordin P, Ibingira C, Forsberg BC, Wladis A (2014) Prevalence of treated and untreated groin hernia in eastern Uganda. Br J Surg 101:728-734

112. Beard JH, Oresanya LB, Akoko L, Mwanga A, Dicker RA, Harris HW (2014) An estimation of inguinal hernia epidemiology adjusted for population age structure in Tanzania. Hernia 18(2):289-295

113. Beard JH, Oresanya LB, Ohene-Yeboah M, Dicker RA, Harris HW (2013) Characterizing the global burden of surgical disease: a method to estimate inguinal hernia epidemiology in Ghana. World J Surg 37(3):498-503

114. Ohene-Yeboah M, Abantanga FA (2011) Inguinal hernia disease in Africa: a common but neglected surgical condition. West Afr J Med 30(2):77-83

115. Kingsnorth AN, Clarke MG, Shillcutt SD (2009) Public health and policy issues of hernia surgery in Africa. World J Surg 33(6):1188-1193

116. Higashi H, Barendregt JJ, Kassebaum NJ, Weiser TG, Bickler SW, Vos T (2015) Surgically avertable burden of obstetric conditions in low- and middle-income regions: a modelled analysis. BJOG An Int J Obstet Gynaecol 122(2):228-236

117. Gagliardi AR, Brouwers MC, Palda VA, Lemieux-Charles L, Grimshaw JM (2009) An exploration of how guideline developer capacity and guideline implementability influence implementation and adoption: study protocol. Implement Sci 4:36

118. Datta N, MacQueen IT, Schroeder AD, Wilson JJ, Espinoza JC, Wagner JP, Filipi CJ, Chen DC (2015) Wearable technology for global surgical teleproctoring. J Surg Educ 72(6):1290-1295

119. Lofgren J, Nordin P, Ibingira C, Matovu A, Galiwango E, Wladis A (2016) A Randomized trial of low-cost mesh in groin hernia repair. N Engl J Med 374:146-153

120. World Alliance for Patient Safety (2008) Second Global Patient Safety Challenge: Safe Surgery Saves Lives. WHO Press, Geneva

121. Schünemann HJ, Fretheim A, Oxman AD (2006) Improving the use of research evidence in guideline development: 13. Applicability, transferability and adaptation. Health Res Policy Syst $8(4): 25$

122. MacCormick AP, Akoh JA (2018) Survey of surgeons regarding prophylactic antibiotic use in inguinal hernia repair. Scand J Surg 107(3):208-211 
123. Ishikawa S, Kawano T, Karashima R, Arita T, Yagi Y, Hirota M (2015) A case of mesh plug migration into the bladder 5 years after hernia repair. Surg Case Rep 1(1):4

124. Bratzler DW, Dellinger EP, Olsen KM, Perl TM, Auwaerter PG, Bolon MK, Fish DN, Napolitano LM, Sawyer RG, Slain D, Steinberg JP, Weinstein RA, American Society of Health-System Pharmacists (ASHP); Infectious Diseases Society of America (IDSA); Surgical Infection Society (SIS); Society for Healthcare Epidemiology of America (SHEA) (2013) Clinical practice guidelines for antimicrobial prophylaxis in surgery. Surg Infect (Larchmt) 14(1):73-156

125. Zamkowski MT, Makarewicz W, Ropel J, Bobowicz M, Kąkol M, Śmietański M (2016) Antibiotic prophylaxis in open inguinal hernia repair: a literature review and summary of current knowledge. Wideochir Inne Tech Maloinwazyjne 11(3):127-136

126. Weyhe D, Winnemoller C, Hellwig A, Meurer K, Plugge H, Kasoly K, Laubenthal H, Bauer KH, Uhl W (2006) (Section sign) $115 \mathrm{~b}$ SGB V threatens outpatient treatment for inguinal hernia. Anal Outcome Econ Chirurg 77(9):844-855

127. Scarfe A, Duncan J, Ma N, Cameron A, Rankin D, Karatassas A, Fletcher D, Watters D, Maddern G (2018) Day case hernia repair: weak evidence or practice gap? ANZ J Surg 88(6):547-553

128. Zollinger RM (2003) Classification systems for groin hernias. Surg Clin North Am 83(5):1053-1063

129. Holmer H, Lantz A, Kunjumen T, Finlayson S, Hoyler M, Siyam A, Montenegro H, Kelley ET, Campbell J, Cherian MN, Hagander L (2015) Global distribution of surgeons, anaesthesiologists, and obstetricians. Lancet Glob Health 27(3 Suppl 2):S9-11

130. Waggoner J, Carline JD, Durning SJ (2016) Is there a consensus on consensus methodology? Descriptions and recommendations for future consensus research. Acad Med 91(5):663-668

131. Jones J, Hunter D (1995) Consensus methods for medical and health services research. BMJ 311(7001):376-380

132. Hsu CC, Sandford BA (2007) The Delphi technique: making sense of consensus. Pract Assess Res Eval 12:10

133. Dalkey NC, Helmer O (1963) An experimental application of the Delphi method to the use of experts. Manage Sci 9(3):458-467
134. Boulkedid R, Abdoul H, Loustau M, Sibony O, Alberti C (2011) Using and reporting the Delphi method for selecting healthcare quality indicators: a systematic review. PLoS ONE 6(6):e20476. https://doi.org/10.1371/journal.pone.0020476

135. Nair R, Aggarwal R, Khanna D (2011) Methods of formal consensus in classification/diagnostic criteria and guideline development. Semin Arthritis Rheum 41:95-105

136. Rycroft-Malone J (2001) Forrmal consensus: the development of a national clinical guideline. Qual Health Care 10:238-244

137. Loblaw DA, Prestrud AA, Somerfield MR, Oliver TK, Brouwers MC, Nam RK, Lyman GH, Basch E, Americal Society of Clinical Oncology Clinical Practice Guidelines (2012) American Society of Clinical Oncology Clinical Practice Guidelines: formal systematic review-based consensus methodology. J Clin Oncol 30:3136-3140

138. Gorter RR, Eker HH, Gorter-Stam MA, Abis GS, Acharya A, Ankersmit M, Antoniou SA, Arolfo S, Babic B, Boni L, Bruntink M, van Dam DA, Defoort B, Deijen CL, DeLacy FB, Go PM, Harmsen AM, van den Helder RS, Iordache F, Ket JC, Muysoms FE, Ozmen MM, Papoulas M, Rhodes M, Straatman J, Tenhagen M, Turrado V, Vereczkei A, Vilallonga R, Deelder JD, Bonjer J (2016) Diagnosis and management of acute appendicitis EAES consensus development conference 2015. Surg Endosc 30(11):4668-4690

139. American Society of Anesthesiologists (2018) Practice advisory for the prevention of perioperative peripheral neuropathies 2018: an updated report by the American Society Of Anesthesiologists task force on prevention of perioperative peripheral neuropathies. Anesthesiology 128(1):11-26

Publisher's Note Springer Nature remains neutral with regard to jurisdictional claims in published maps and institutional affiliations. 